\title{
10 year review of cardiac tumours in childhood
}

L Abushaban, B Denham, D Duff

\begin{abstract}
Objective-To review the commonest types of cardiac tumours in childhood, their different presentations, and management.

Design-A retrospective study of patients with cardiac tumours.

Setting-Cardiac department of a teaching hospital.

Patients-Six patients with an age range between one day to three years presented over a period of 10 years.

Main outcome measures-To determine different presentations, management, and prognosis of cardiac tumours.

Results-Three patients presented with an arrhythmia, two with an asymptomatic heart murmur, and the sixth was discovered accidentally. Surgical resection of the tumours was performed in five cases, one patient died during the operation, one developed new tumours after surgery, and the remaining three have had an excellent result. Histology of those operated on showed benign rhabdomyomas in three and fibromas in the other two. The sixth patient was managed conservatively and the multiple tumours he had showed gradual resolution over a period of 10 months follow up. One baby with rhabdomyoma had signs of tuberous sclerosis whereas the others were normal at follow up five months to three years after diagnosis, None of them had a positive family history.

Conclusion-Cardiac tumours in childhood are extremely rare. The commonest types are rhabdomyomas, then fibromas. Most cases are diagnosed by echocardiography. The prognosis for most patients is excellent.
\end{abstract}

\section{(Br Heart f 1993;70:166-169)}

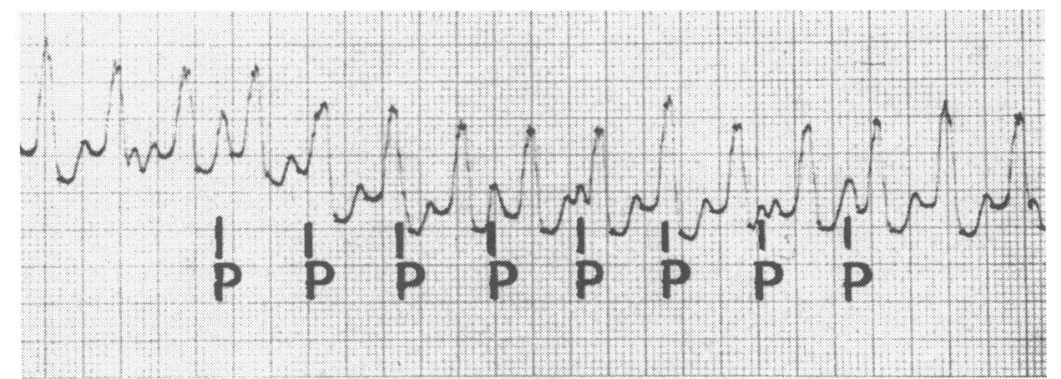

Figure 1 Electrocardiogram of patient 1 with a cardiac fibroma, showing ventricular tachycardia with a ventricular rate of 166 beats/min; atrial rate is 125 beats/min.
Primary cardiac tumours are very rare in all age groups. The incidence at paediatric necropsies is reported to be $0.027 \% .^{1}$ The commonest primary tumour in childhood is a rhabdomyoma, ${ }^{2}$ then fibroma. ${ }^{3}$ Others like teratomas, ${ }^{4}$ myxomas, ${ }^{5}$ and mesotheliomas ${ }^{6}$ have also been reported. We reviewed a total of six cases of primary cardiac tumours seen at Our Lady's Hospital For Sick Children over a period of 10 years.

\section{Case reports}

CASE 1

A boy aged 2 years and 10 months was admitted with severe congestive cardiac failure and ventricular tachycardia in 1981 (fig 1). He was pale, dyspnoeic, and oedematous. He underwent synchronised cardioversion shortly after admission with a return to sinus rhythm. The electrocardiogram in sinus rhythm showed a pattern of myocardial infarction of the lateral wall of the left ventricle, but the cardiac enzymes were normal. A chest $x$ ray film showed cardiomegaly with a shelf like left cardiac border (fig 2). A dilated left ventricle with very depressed systolic function and a shortening fraction of $10 \%$ was found on $M$ mode echocardiography. A

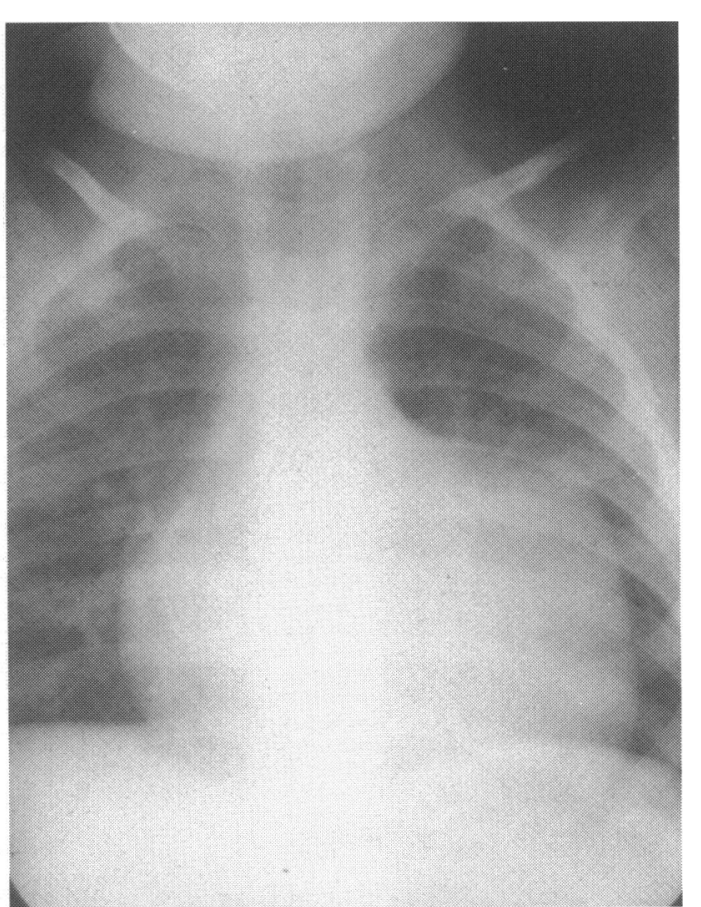

Figure 2 Chest $x$ ray film of patient 1 showing cardiomegaly and a shelf-like left cardiac border. 
thallium scan did not show any definite area of decreased uptake. The differential diagnosis was of myocarditis or anomalous origin of the left coronary artery from the pulmonary artery, but because of atypical features cardiac catheterisation was performed and showed a large solitary tumour within the wall of the left ventricle that was compressing the left ventricular cavity and stretching the left coronary vessels. He underwent surgery with partial excision of the tumour. Complete excision was not feasible because of the extent of the tumour, which replaced more than $50 \%$ of the left ventricular myocardium. He failed to come off the cardiopulmonary bypass. Histology showed a benign fibroma.

\section{CASE 2}

A 2 year and 10 month old boy was referred for the assessment of a heart murmur that was discovered accidentally in 1984 . He was symptom free. On examination he had normal pulses and a prominent thrill at the pulmonary area. There was grade $4 / 6$ systolic murmur at the pulmonary area and a diastolic murmur at the lower left sternal border. The electrocardiogram showed right axis deviation and right ventricular hypertrophy, whereas the chest $x$ ray film was normal. A clinical diagnosis of pulmonary stenosis was made. A cross sectional echocardiogram showed a solitary cardiac tumour in the right ventricle attached to the septal surface and to the right ventricular outflow tract (fig 3). At cardiac catherisation there was a gradient of only 6 $\mathrm{mm} \mathrm{Hg}$ across the right ventricular outflow tract. The tumour was excised without complications. Histology showed a benign fibroma. The patient made an excellent recovery and he is symptom free seven years after surgery with no recurrence of the tumour.

\section{CASE 3}

In 1987 a preterm male infant was born by lower segment caesarian section because of pre-eclamptic toxaemia. The birth weight was $1.460 \mathrm{~kg}$. He was managed in a special care baby unit for seven weeks after birth. He was

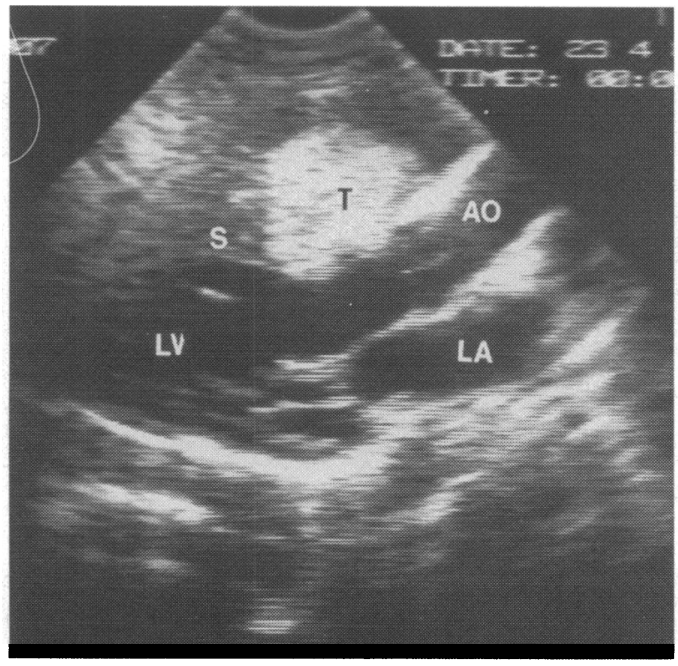

Figure 3 An echo-dense mass (T) fibroma is seen occupying the right ventricular outflow tract in patient 2. referred for cardiac assessment at the age of 2 months because of cardiomegaly on chest $x$ ray film and an electrocardiogram that showed Wolff-Parkinson-White type b pattern. He was symptom free and had a normal clinical examination. A cross sectional echocardiogram showed a $1 \mathrm{~cm}$ tumour situated in the right ventricular cavity in the region of the membranous septum. He remained symptom free with no change of tumour size over a period of one year. When elective surgery was performed, the tumour was found to be encapsulated and was 1.25 $\mathrm{cm}$ in diameter. Histology showed a benign rhabdomyoma. The postoperative period was uneventful. He has remained symptom free with no recurrence of the tumour over two years of follow up. He still has WolffParkinson-White pattern on his electrocardiogram. He does not have any manifestation of tuberous sclerosis. His parents are also normal.

\section{CASE 4}

A 2 week old male infant was referred for the assessment of a symptom free heart murmur in 1989. He was a full term infant with a birth weight of $3.8 \mathrm{~kg}$. He had no immediate perinatal problems. He was the third baby to healthy parents and other siblings were normal. He was acyanotic and in no distress but had low volume pulses. He had a grade $3 / 6$ harsh systolic murmur best heard at the left sternal border suggestive of a small ventricular septal defect. The electrocardiogram showed right ventricular dominance but otherwise was normal. A chest $x$ ray film showed mild cardiomegaly with prominence of the left heart border and a low apex suggestive of left ventricular hypertrophy. A cross sectional echocardiogram showed a tumour in the left ventricular outflow tract arising from the septum, it was obstructive with $75 \%$ occlusion of the aortic orifice, although left ventricular function seemed normal. Resection of the tumour at 3 weeks of age was successful. Histology showed a benign rhabdomyoma. He has remained clinically well with no recurrence of the tumour on follow up over one year and eight months. He has not shown any manifestation of tuberous sclerosis.

CASE 5

A male infant with a birth weight of $3.65 \mathrm{~kg}$ was referred in 1989 at the age of 2 days because of feeding difficulty and tachypnoea that began a few hours after birth. On examination he was in congestive cardiac failure with a heart rate of 270 beats $/ \mathrm{min}$ and the electrocardiogram showed a supraventricular tachycardia that settled after digitalisation. He had a hyperactive precordium but no murmurs were heard. His liver was $2 \mathrm{~cm}$ below the costal margin. The chest $x$ ray film showed a normal heart size. In sinus rhythm the electrocardiogram was normal. A cross sectional echocardiogram showed a tumour which was $12 \mathrm{~mm}$ in diameter in the right ventricular cavity, with a second small tumour high in the septum at the right ven- 
tricular outflow tract. Cardiac catheterisation showed that the tumour in the right ventricular outflow tract was not obstructive. Surgery was performed at the age of one month at which time four tumours were removed. One was excised from the right atrium, a second from the right atrial appendage, a third from the right ventricular free wall, and the fourth from the right ventricular outflow tract. After surgery cardiac rhythm was normal. He was discharged on verapamil. Histology showed a benign rhabdomyoma. Two weeks after surgery cross sectional echocardiography showed new tumours, one near the left ventricular apex, a second at the perimembranous area on the right side of the septum, a third in the right ventricular apex, and a fourth on the right ventricular papillary muscle. He was admitted one month after surgery with two episodes of supraventricular tachycardia, both of which responded to verapamil. Repeated follow up cross sectional echocardiograms showed a gradual resolution of the tumours at the right ventricular septum and right ventricular papillary muscles, but tumours at the left and right ventricular apices were still present. He has tuberous sclerosis, has developed depigmented skin lesions and was admitted to hospital at the age of 18 months with convulsions. A computerised axial tomogram of the brain showed periventricular calcification. Examinations of the parents and sibling were normal and there is no family history of tuberous sclerosis.

\section{CASE 6}

A male infant, full term normal delivery with a birth weight of $4.20 \mathrm{~kg}$, was referred in 1990 at the age of 16 days because of feeding difficulty and tachypneoa. On examination he was in distress with signs of congestive cardiac failure and a pronounced tachycardia. The electrocardiogram showed supraventricular tachycardia with a rate of 280 beats $/ \mathrm{min}$. In sinus rhythm the electrocardiogram was normal. His supraventricular tachycardia failed to respond to digoxin but eventually was controlled by verapamil. A chest $x$ ray film showed cardiomegaly. A cross sectional echocardiogram showed multiple tumours of the heart. Two were at the apex of the right ventricle, a third at the apex of the left ventricle, and a fourth at the left ventricular outflow tract was non obstructive (fig 4). Sinus rhythm was maintained with verapamil and digoxin. The baby was discharged well and symptom free. After 10 months of follow up the tumours have regressed completely. The baby had no evidence of tuberous sclerosis. His parents are normal.

\section{Discussion}

Cardiac tumours in infants and children are extremely rare, and presentation in infancy is uncommon. In 1965, 15 European cardiac centres collected 22 cases of cardiac tumours in children. Only nine were found in infants. ${ }^{7}$ Boston Children's Hospital reported three infants with symptomatic tumours out of 11000 necropsies between 1914 and $1966 .{ }^{1}$ Of the six cases in our series four of them were infants below the age of 2 months and the other two were below 3 years of age. All our cases were males, but we have no evidence to suggest that this occurrence was anything other than chance; no sex difference was reported in previous studies. Cardiac tumours may present with features of obstructed blood flow ${ }^{8}$ as in case 2 who had a murmur of pulmonary stenosis, and in case 4 who had in retrospect a murmur related to subaortic stenosis rather than a ventricular septal defect. Arrhythmias are frequent ${ }^{3}$ and may be the presenting feature as in cases 1,5 and 6 . Alternatively the child with a tumour may be symptom free ${ }^{9}$ or the tumour may be detected by chance as in case 3 . Cross sectional echocardiography is the most sensitive test for diagnosing cardiac tumours and for the most part cardiac catherisation and angiography are unnecessary. In case 1, a cross sectional echocardiogram was not yet obtainable in our institution and $M$ mode echocardiography suggested a congestive cardiomyopathy; cardiac catheterisation was

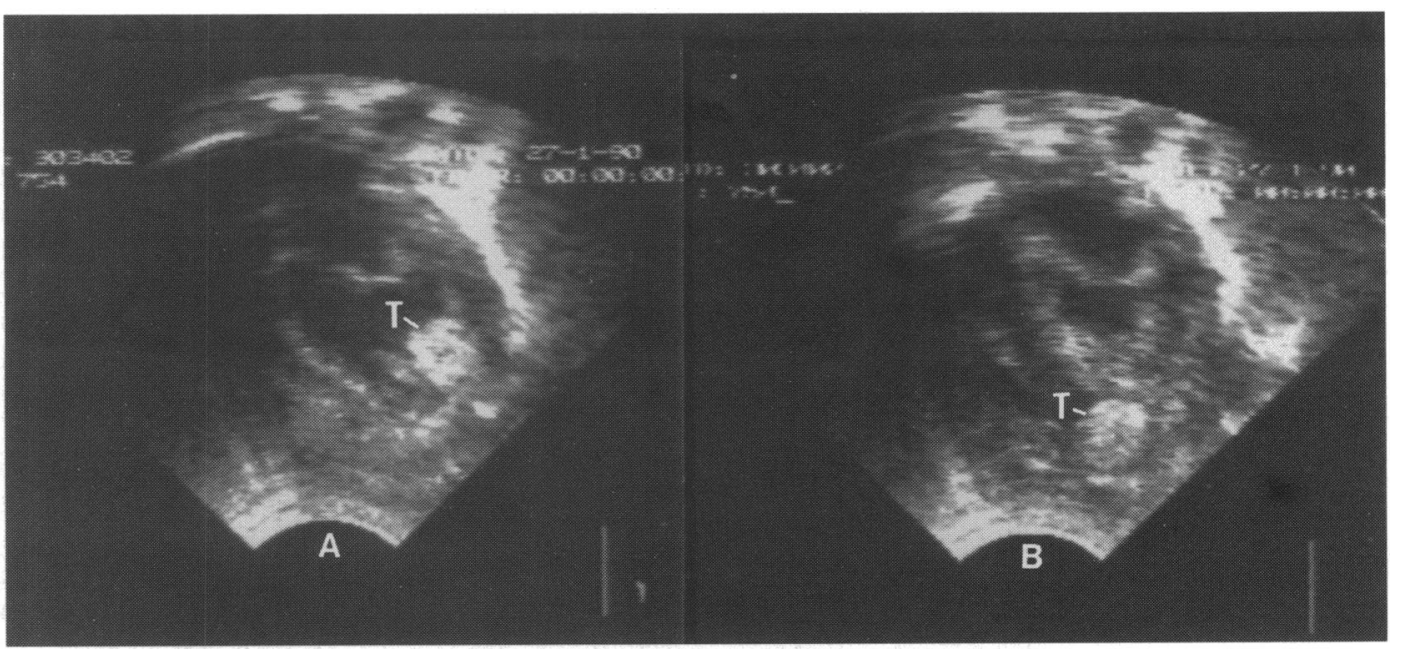

Figure 4 Tumours $(T)$ in the left ventricle (panel A) and in the right ventricle (panel B) in patient 6. 
therefore used to establish the diagnosis. The invasive studies used in cases 2 and 5 added little additional information and did not influence management. Magnetic resonance imaging or computed tomography have been used by some centres to delineate the extent of the tumour mass in the myocardium. ${ }^{1011}$

Rhabdomyomas are the most frequent heart tumours in newborn infants and young children. Three and perhaps four of our cases had rhabdomyomas, cases $3,4,5$, and 6 . One of them had multiple lesions and developed new tumours after surgery. These have, however, shown gradual resolution. One baby, case 6 , who had multiple tumours did not undergo surgery and therefore no histology is available. The behaviour and multiplicity of his tumours, however, strongly suggest a rhabdomyoma. 9 The tumours in this case have undergone complete resolution over a period of 10 months. This phenomenon of spontaneous resolution has been described in other series and has important implications for management. ${ }^{12}$ Surgical treatment is probably only necessary when the tumours create an impediment to blood flow or are associated with life threatening arrhythmias such as ventricular tachycardia. ${ }^{9}$ It may be possible to obtain an histological diagnosis with a biopsy catheter ${ }^{13}$ or by fine needle aspiration. ${ }^{14}$ Cases 1 and 2 had fibromas and they were both solitary tumours. A presentation of ventricular tachycardia in a previously well child or an unusual cardiac outline of the left cardiac border on the chest radiograph (case 1) should suggest the possibility of this diagnosis. Of the three or four cases with rhabdomyomas one had signs of tuberous sclerosis, none had a positive family history, and the examinations of all parents and sibling by a neurologist were normal. The quoted incidence of this association is $50 \% .^{15}$ Interestingly another infant seen during this same period had tuberous sclerosis, recurrent supraventricular tachycardia, and WolffParkinson-White syndrome but as yet at least has no detectable cardiac tumour.
In oummary, six cases with primary cardiac tumours were reviewed, rhabdomyomas were the most common type, then fibromas. Our patients were all males and below 3 years of age. One had tuberous sclerosis. The diagnosis of a cardiac tumour should be considered in any infant or child with tuberous sclerosis, or who presents with a tachycardia (especially ventricular), or an abnormal cardiac outline on a chest radiograph. Cross sectional echocardiography is the most sensitive diagnostic procedure. The cardiac prognosis for most patients is excellent.

1 Nadas AS, Ellison RC. Cardiac tumours in infancy. $A m \mathcal{F}$ Cardiol 1968;21:363-6.

2 Arciniegas E, Hakimi M, Farooki $\mathrm{ZK}$, Trucione NJ Green EW. Primary cardiac tumours in children. $f$ Thorac Cardiovasc Surg 1980;79:582-91.

3 Filiatrault M, Bieland MJ, Neilson KA, Paquet $M$ Cardiac fibroma presenting with clinically significant arrhythmias in infancy. Pediatr Cardiol 1991;12:118-20.

4 Costas C, Williams R, Fortune $R$. Intracardiac teratoma in an infant. Pediatr Cardiol 1986;7:179-81.

$5 \mathrm{Hals} \mathrm{J}, \mathrm{Ek} \mathrm{J}$, Sandes K. Cardiac myxoma as the cause of death in an infant. Acta Paediatr Scand 1990;79: 999-1000.

6 Eker R, Cantez T, Dogan O, et al. Pericardial mesothelioma. A pediatric case report. Turk $\mathcal{f}$ Pediatr 1989;31: lioma. A.

7 Van der Hauwert LG. Cardiac tumours in infancy and childhood. Br Heart $\mathcal{f}$ 1971;33:125-32.

8 Skillington PD, Brawn WJ, Menahem ES, et al. Surgical excision of primary cardiac tumours in infancy. Aust NZ excision of primary cardiac

9 Smith HC, Watson GH, Patel RG, Super M. Cardiac rhabdomyomata in tuberous sclerosis: their course and diagnostic value. Arch Dis Child 1989;64:196-200.

10 Rienmuller $R$, Lloret JL, Tiling $R$, et al. MR imaging of pediatric cardiac tumors previously diagnosed by echocardiography. If Comput Assist Tomog 1989;13 621-6.

11 Shiraishi H, Yanagisawa M, Kuramatsu T, et al. Cardiac tumour in a neonate with tuberous sclerosis: echocardiographic demonstration and magnetic resonance imaging. Eur $\mathcal{f}$ Pediatr 1988;148:50-2.

12 Farooki ZK, Ross RD, Paridon SM, et al. Spontaneous regression of cardiac rhabdomyoma. Am $\mathcal{f}$ Cardiol regression of

13 Bini $R M$, Westaby $S$. Investigation and management of primary cardiac tumors in infants and children. $₹ \mathrm{Am}$ Coll Cardiol 1983;2:351-7.

14 Moriarty AT, Nelson WA, McGahey B. Fine needle aspiration of rhabdomyosarcoma of the heart. Light and electron microscopic findings and histological correlation. Acta Cytol 1990;34:74-8.

15 Harding CO, Pagon RA. Incidence of tuberous sclerosis in patients with cardiac rhabdomyoma. Am $\mathcal{F}$ Med Genet 1990;37:443-6. 